\title{
Türkiye'nin ilk sanal herbaryumu IZEF örneği ve sanal herbaryumlarmn bitkisel ilaç hammaddesi araştırmaları açısından önemi
}

\author{
Bintuğ ÖZTÜRK, Mehmet Ali EGE
}

\section{ÖZET}

AMAÇ: Bu çalışmada; Türkiye'nin ilk sanal herbaryumu olan IZEF (İzmir, Ege Üniversitesi Eczacılık Fakültesi Herbaryumu) örneğine dayanarak, sanal herbaryumlara dönüşüm için bir yol haritasının sunulması ve sanal herbaryumlarınbitkisel kaynaklı ilaç hammaddesi araştırmalarında üstlenebileceği önemli rolün ortaya konması amaçlanmıştır.

METOD: IZEF herbaryumunda kayıtlı 6000 herbaryum örneğine ait veri ve görüntüler, hazırladığımız "Türkiye Floras1 1.0" ve "IZEF Herbaryum 1.0" adlı veri tabanı yazılımları yardımıyla, sanal hale dönüştürülmüştür.

BULGULAR: Türkiye'nin ilk Sanal Herbaryumu IZEF, tüm örneklerine ait veri ve görüntüleri ile www.izef.ege.edu.tr adresinden araştırmacıların hizmetine sunulmuştur.

Anahtar Kelimeler: Sanal herbaryum, herbaryum, IZEF, Türkiye floras 1
Bintuğ Öztürk

Ege Üniversitesi, Eczacllık Fakültesi, Farmasötik Botanik Anabilim Dall, 35100, Bornova-İzmir,Türkiye

Mehmet Ali Ege

Ege Üniversitesi Eczacıllk Fakültesi, Farmasötik Teknoloji Anabilim Dall, 35100, Bornova-İzmir, Türkiye

İletişim:

Bintuğ Öztürk

E-posta: bintug.ozturk@ege.edu.tr

Tel: +902323112239

Fax: +902323885258

\section{GíRiş}

İlaç, gıda, kozmetik, yada diğer endüstri dallarına yönelik hammadde kaynağı olabilecek bitkileri bulundurma potansiyelleri nedeniyle, yeni keşfedilen bölgelerin floraları, her dönemde araştırmacıların dikkatini çekmiştir (1). Flora araştırmaları biyoçeşitlilikten beslenen tüm disiplinler için doğal kaynak araştırmalarının en önemlilerindendir. Araştırmacılar topladıkları bitki örneklerini korumak ve saklamak için yassılaştırarak kurutmayı keşfetmiş ve bu örneklerin korunduğu herbaryumlar kurmuşlardır (2). Her dönem ve disiplin, kendi bilgi birikimi ve teknolojisiyle, elde edilen değerli örnekleri ve bunlara ait bilgileri derlemeye, kayıt altına almaya, korumaya ve yönetmeye çabalamıştır. Günümüzde bu çabaya bilgisayarlar, yazılımlar, veritabanları, dijital kameralar, GPS sistemleri ve internet de dahil olmuştur (3).

Sanal herbaryum, dijital herbaryum yada interaktif herbaryum, bir bitki koleksiyonuna ait tüm verilerin yönetilmesinde en üst düzeyde verimliliği ve yararlılığ1 hedefleyen bir herbaryum veritabanı olarak tanımlanmaktadır. (4). 20 yılı aşkın süredirbaşta ABD olmak üzere dünyanın farklı ülkelerindekiherbaryumlarda yer alan örneklerin etiket bilgileri ve görüntülerinin dijital ortama aktarılıp yönetilmesiyle sanal herbaryumlar oluşturulmaya başlanmıştır (5).

Türkiyeflorasında yer alan bitkilere ait verileri daha etkin ve verimli yönetebilmek konusundaki çabalardaha çok bitki veri tabanlarının oluşturulması şeklinde son yirmi yıl içerisinde artan şekilde devam etmiştir. Ülkemizde bitki veritabanı çalışmalarının ilkleri Babaç ve arkadaşlarınca 1985 yılında hazırlanan Elazı ̆ yöresinde yayılış gösteren "Leguminosae BitkileriVeritabanı", 
1987 yılında GWBasicile hazırlanan"Malatya-Pötürge Yöresi FloristikVeritabanı", dBASE II ile hazırlanan "Malatya Yöresinin T1bbi ve Endüstriyel Bitkileri Veritabanı" ve 1988'de dBASEIII+ ile hazırlanan Türkiye "Leguminosae Bitkileri Veritabanı"dır. Bu ilk adımları yine Babaç ve arkadaşlarının 1995 yılında hazırladığı ilk büyük ulusal bitki veritabanılan TUBVET, 1997 yılında TUBITAK ve1998 yılında DPT tarafindan desteklenerek başlatılan ve Türkiye'deki 21 üniversitede yer alan 23 herbaryumdaki 80.000 örneğin verilerinin sayısallaştırılmasını içeren TURKHERB veritabanları izlemiştir (6). Bu çalışmaları, “Türkiye Labiatae'leri Veritabanı" (TULAB), "Türkiye Endemik Bitkileri Veritabanı”, “Türk Halk İlaçları Veritabanı”(7), “Türkiye'nin Sporlu Bitkileri Veritaban1" (TURKKIRP) “Türkiye'nin İletim Demetli Bitkileri Veritabanı" (NOMVET) ve “Türkiye'nin Tatlı Su Algleri Veritabanı" (ALGVET) izlemiştir. 2001 yılında, yirmi yıla yakın süredir çalışılan ve geliştirilen TUBVET verilerinin üzerine inşa edilen ve internet aracılığı ile uzaktan ulaşılabilen Türkiye Bitkileri Veri Sistemi (TÜBİVS), http://www.tubitak.gov.tr/tubives adresinden hizmet vermeye başlamıştır. Bugün ise aynı sistem http://turkherb.ibu.edu.tr/ adresinden hizmet vermeye devam etmektedir (6). 2002 y1linda, 11 ciltlik "Türkiye ve Doğu Ege Adaları Florası"nda kayıtlı taksonlarıntamamını içeren bir veritabanı, ekibimiz tarafından bilimsel amaçl1 ticari bir kaynağa dönüştürülerek "Türkiye Florası 1.0”, (ISBN: 975-97964-3-0) adlı yazılım hazırlanmıştır. Hemen ardından bu yazılıma dayanarak yapılanan "IZEF Herbaryum 1.0" veritabanı ise görsel içerikli gerçek örnek verilerine uzaktan ulaşılabilen, Türkiye'nin ilk sanal herbaryumu olmuştur (http://izef.ege.edu.tr) (8). 2010 yılında yine ekibimizce “Türkiye Florası 1.0" yazılımında yer alan taksonlara ve bunlara aitlokalite verilerine dayanarak Google Earth tabanlı "Türkiye Fitocoğrafya Haritası" adlı Türkiye'nin ilk sayısal fitocoğrafya haritası hazırlanmıştır (9). Yine ekibimiz tarafından 2012 yılında “FFD MonograflarıVeritabanı"(ISBN: 978-975-567-075-1), "Türkiye Tıbbi Bitkileri Bibliyografyası Veritabanı" ve “Türkiye'nin Etnofarmasötik Botanik Kullanımı Bulunan Bitkileri Veritabanı" (10,11,12), 2013 yılında ise “Türkiye'nın Gıda Bitkileri Veritabanı" çalışmaları tamamlanmıştır (13). Herbaryumların geçmişte sayısallaşan verilerinin güncel yazılımlara ve görsel destekli interaktif kullanımına yönelik dönüşüm sürecinde, Van 100. Y11 Üniversitesi Herbaryumu, Gazi Üniversitesi Fen Fakültesi Herbaryumu (GAZI), Ístanbul Üniversitesi Orman Fakültesi Herbaryumu (ISTO), İstanbul Üniversitesi Fen Fakültesi Herbaryumu (ISTF) ve İstanbul Üniversitesi Eczacılık Fakültesi Herbaryumu (ISTE)ilk adımları atan herbaryumlardır(8,9).

Bu çalışmada; Türkiye'nin ilk sanal herbaryumu olan IZEF örneğine dayanarak, görsel destekli uzaktan erişilebilir sanal herbaryumlara dönüşümüne ait bir yol haritasının sunulması vesanal herbaryumların yaygınlaşmasınınbitkiselkaynaklı ilaç hammaddesi araştırmalarında üstlenebileceği önemli rolün ortaya konması amaçlanmıştır.

\section{GEREÇ VE YÖNTEM}

$\mathrm{Bu}$ araştırmada; beta sürümleri adım adım geliştirilen "Türkiye Floras1 1.0" ve "IZEFHerbaryum 1.0" adlı 2 farklı veritabanı programı, bu programını hazırlayıp geliştirmek için kullanılan yazılımlar, Türkiye florası bitkilerine ait bilgiler ve IZEF herbaryumu örneklerine ait veriler araştırma materyali olarak kullanılmıştır. Türkiye florası bitkilerine ait bilgiler, 11 ciltlik "Türkiye ve Doğu Ege Adaları Florası" adlı ana kaynakta yer alan verilerle (14-24), herbaryumveritabanı ile ilgili kısmı ise IZEF'te yer alan ilk 6000 bitki örneğine ait veriler ile sınırlandırılmıştır. Hazırladığımız "Türkiye Florası1.0" ve "IZEF Herbaryum 1.0" veritabanlar."Microsoft Access" ile oluşturulmuştur.Veri giriş yazılımlarında (Integrated Development Environment IDE) profesyonel yazılım geliştirmek için kullanılan genel amaçlı bir bilgisayar programlama dili olan, "BorlandDelphi5.0" kullanılmıştır. $(25,26)$. Bu ortamda görsel ögeler ve kullanıcı arayüzüBorland'ın Visual Components Library (VCL) kütüphanesi kullanılarak geliştirilmiştir. Programda yer alan "Botanik Terimleri Sözlügü" ve familya genel bilgileri dosyaları "Microsoft Word" ile oluşturulup veri tabanına eklenmiştir. Çalışmada kullanılan herbaryum örneklerine ait fotoğrafların çekimi Leica Makro çekim standına bağlı,NikonCoolpix dijital fotoğraf makinesi ile gerçekleştirilmiştir. Programda yer alan fotoğrafların hazırlanmasında "AdobePhotoshop7.0" kullanılmıştır. Veritabanına aktarılan bilgilerin internette yayınlanabilmesi için Windows Server 2000 kullanılmıştır. Servis olarak Internet Information Server (IIS) web sayfası dili olarak ASP kullanılmıştır. İnternet sayfasının tasarımında Macromedia Dreamveawer kullanılmıştır.

Herbaryum veri tabanlarında örnek ve otör adlarının her seferinde yeniden yazımı sırasında yazım hatalarının oluşabildiği bilinmektedir. $\mathrm{Bu}$ hatalar tarih, rakım ve lokalite bilgilerinin kayd1 sırasında de meydana gelebilmektedir. Veri tabanlarının temel işleyiş prensibine göre bir veri nasıl kaydedilmişse, ileride ancak kaydedildiği biçimde sorgulanabilmektedir. Eski yazılımlarda herbaryum örnek bilgilerinin kaydı sırasında sıklıkla karşılaşılan hatalar arasında; harf hataları, noktalama işareti hataları, kelimeler arasında bir yerine iki boşluk verilmesi gibi durumlar, kaydedilen verinin sorgulanması sırasında bir engel olarak ortaya çıkmaktadır. $\mathrm{Bu}$ durum sağlıklı işleyen bir bitki veritabanı önündeki en önemli engellerden biridir.Bu zorluğun aşılmasının tek yolu Türkiye florasında kayıtlı bitki adlarının, otör adlarının ve bunlara ait bazı bilgilerin, sistematik birveritabanı mantığı içerisinde, bir sefere mahsus olarak, tek tek ana bir ulusal flora veritabanına aktarılmasıdır. Böylece ileride herbaryum örneği kaydı sırasında bitki ile ilgili bilgiler elle yazılmayıp, menüden seçmek yoluyla kaydedilebilmektedir. Benzer şekilde tarih, rakım, koordinat hatta il ve ilçeler de önceden ana veritabanına, ayrı menüler şeklinde kaydedilerek hatalı veri girişininönlenebildiği ortaya konmuştur (7). Bu bilgiler 1şı̆̆ında araştırma yöntemimiz, IZEF örneği deneyimimize dayanarak ayrıntılı bir şekilde aşağıda aktarılmıştır.

Bir herbaryumun sayısallaştırılması dünyadaki diğer örneklerde de benzer temel adımlar takip edilerek gerçekleştirilmektedir $(27,28)$. Ayrıntıda daha fazla adımı içersede bu ortak adımlar 6 ana aşamada toparlanabilir:

1. Ulusal flora veritabanının hazırlanması ya da temini.

2. Herbaryumveritabanının veri giriş yüzünün hazırlanması ya da temini.

3. Veri giriş yüzüne demirbaş numarası almış teşhisli ve etiketli örneklere ait bilgilerin kaydedilmesi.

4. Demirbaş numarası almış teşhisli ve etiketli örneklerin görüntülenmesi ve önceden kaydedilmiş verilerle bu görüntülerin eşleştirilmesi. 


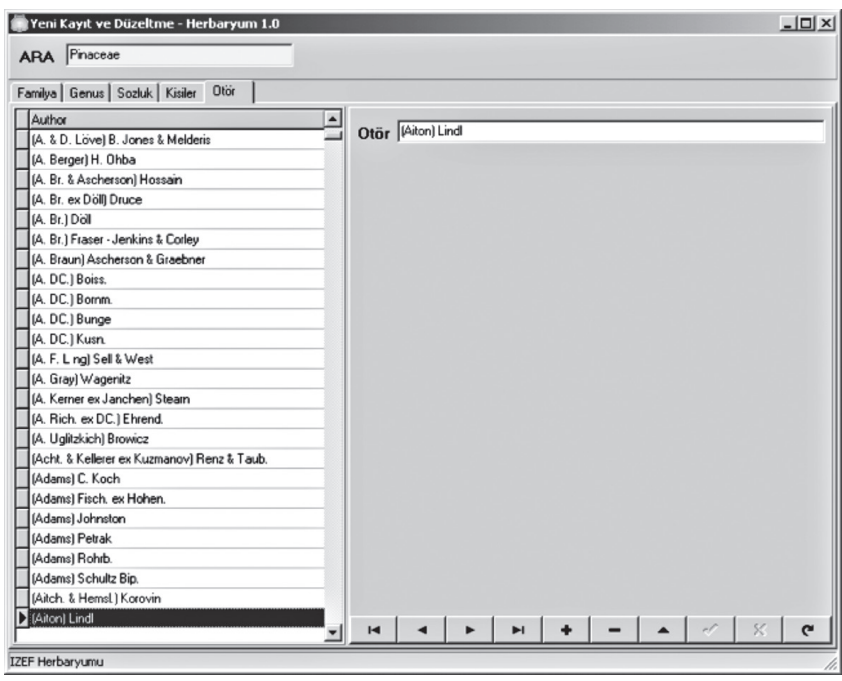

Resim 1: Otör adı veri giriş ekranı

5. Örneklere ait bilgi ve görüntülerle desteklenmiş herbaryumveritabanının kullanıcı yüzünün hazırlanması.

6. Bu verilere internet aracılığı ile uzaktan ulaşılabilirliğin sağlanmasi.

Çalışmamızın ilk adımında, yöntem bilgilerinin ilk paragrafında belirttiğimiz hassasiyetler doğrultusunda,Resim 1-3'de sunulan veri giriş yüzlerine, Türkiye florasındayer alan bitkilerin kaydı ile Türkiye florası veritabanı tamamlanmıştır.Bu adımda Ege adalarında yer alan bitkiler, kültür bitkileri, varlığ şüpheli taksonlar ve son ciltlerde yer alan revizyonlar dikkate alınmış ve özel işaretlerle tanımlanmışlardır. Kaydedilen familyalara ait genel bilgilerin yanı sıra, bitkilere ait endemizm ve flora elementi bilgilerine yer verilmiştir. Yazılımın ilerleyen versiyonlarında içerikleri doldurulmak üzere IUCN kategorisi, ömür, habitat, çiçeklenme gibi bilgilere ait paketler de oluşturulmuştur. $\mathrm{Bu}$ sayede sistematik şekilde kaydedilen bitki taksonları, dahil oldukları familyalar altında Resim 4'deki ara yüzde görüldüğü gibi sorgulanabilmektedirler.

IZEF herbaryumveritabanının oluşturulmasında ise Resim 5 ' de görülen herbaryum veri giriş yüzü kullanılmıştır. Bu bölümde herbaryum örneklerine ait 29 ayrı bilgi paketi yer almaktadır. $\mathrm{Bu}$ bilgi paketleri mevcut herbaryum örneklerine ait etiketlere dayanılarak doldurulmuştur. Toplanan örneğe yönelik ileri araştırmaların yürütülebileceği olasılığı göz önüne alınarak hazırlanan bilgi paketlerinin başlıkları Tablo 1'de listelenmiştir. Herbaryum veri giriş yüzünde yer alan bilgi paketlerinin sağ taraflarında aşağıya doğru ok işareti taşıyanlar, verilerin menülerden seçim yoluyla girilebildiği paketlerdir. Aynı ara yüz ekranının sağ kısmında ise söz konusu olan herbaryum örneğine ait yakınlaştırılabilir fotoğrafik görüntü yer almaktadır.

\section{SONUÇ VE TARTIŞMA}

IZEF'de yer alan örneklere ait bilgilerin bir kısmı, TURKHERB veritabanında yer alan herbaryumlardakine benzer bir şekilde, DOS ortamına Fortran programlama dili aracılığı ile Prof. Dr. Necmettin ZEYBEK ve Prof. Dr. ErhardSAUER'in katkılarıyla

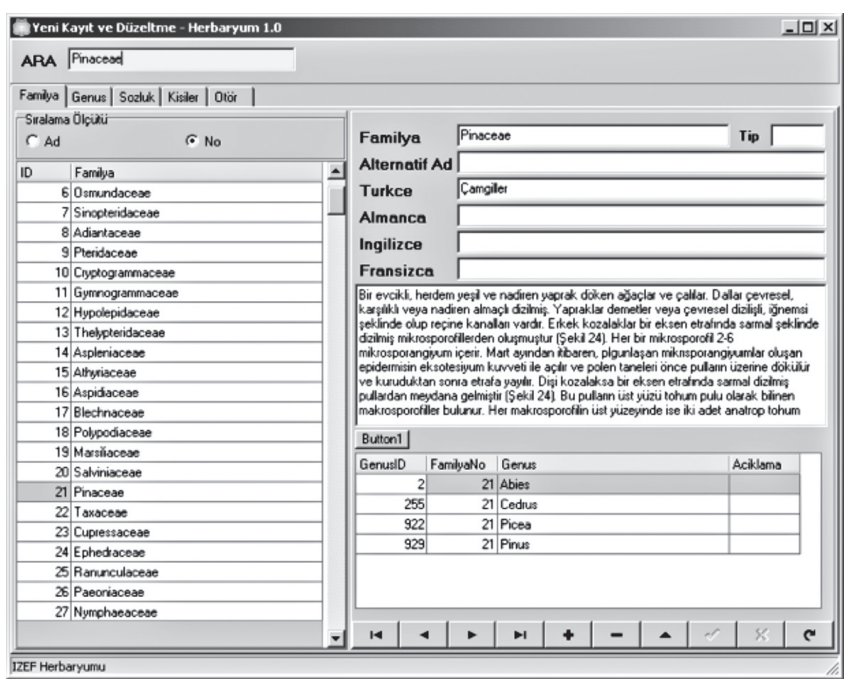

Resim-2: Familya veri giriş ekranı

aktarılmıştı. Söz konusu verilerde düzenleme ve yazım standardizasyonunu takiben, diğer örnek bilgilerinin yeni herbaryum veri giriş yüzüne kaydedilmesiyle, 6000 bitki taksonuna ait lokalite bilgileri sayısal hale getirilmiştir. Her bir örneğe ait herbaryum fotoğrafı çekilmiş ve demirbaş numaraları yardımı ile etiket verileriyle eşleştirilmiştir.

Sanal herbaryuma dönüşüm sürecinde bazı teknik ve temel zorlukların varlığı da göz ardı edilmemelidir. Teknik zorlukların başında donanımsal yetersizlikler, geliştirilme sürecinde sıklıkla revize edilmek zorunda kalınan veritabanı yazılımı ve işlenmiş verilerin kaybedilme olasılığına karşı sıklıkla kopyalanması gelmektedir. Bir diğer teknik zorluk da çekilen fotoğrafların yüksek çözünürlüklü ve gölgesiz olması gerekliliğidir.

Başta eczacılık fakülteleri herbaryumları olmak üzere pek çok herbaryumun yöneticileri ve araştırmacıları ile yapılan görüşmelerde, Türkiye'de sanal herbaryumların önündeki temel engeller konusundaki değerlendirmeler aşağıdaki 7 madde altında toplanmıştır. Herbaryumlarını sanal hale dönüştürmeyi düşünen araştırmacıların bu başlıklardan herbirinin üzerinde dikkatle durmalarının önemi yadsınamaz.

1. Doğal kaynakların korunması ve yönetilmesi konusunda belirlenen ulusal bilim politikalarının çağdaş teknolojilerle desteklenmesi yönündeki irade eksikliği,

2. Bilgi teknolojileri konusunda farklı bir formasyona ve bu nedenle sınırlı bir altyapıya sahip yöneticilerin, söz konusu vizyona yönelik etkin liderlik sergileyememeleri,

3. Başta bilgi ve iletişim teknolojileri konusunda yetişmiş eleman eksiği olmak üzere, teknik alt yapı ve araştırma fonu eksiği,

4. Uzun yıllar süren çabalarla oluşturulmuş herbaryumlardaki örneklere ait verilerin kontrolsüzce paylaşılması sonrasında, bilgilere ulaşanların masa başından yeni tür ya da flora çalışmaları yayınlamaları gibi etik dışı bilimsel uygulamalara yönelebileceklerine dair endişeler,

5. Tehdit altındaki taksonların yanı sıra, uyuşturucu ve zehirli bitkilere ait lokalite bilgilerinin uzman olmayanlar ya da kötü niyetli kişilerin eline geçebileceği kaygısı, 


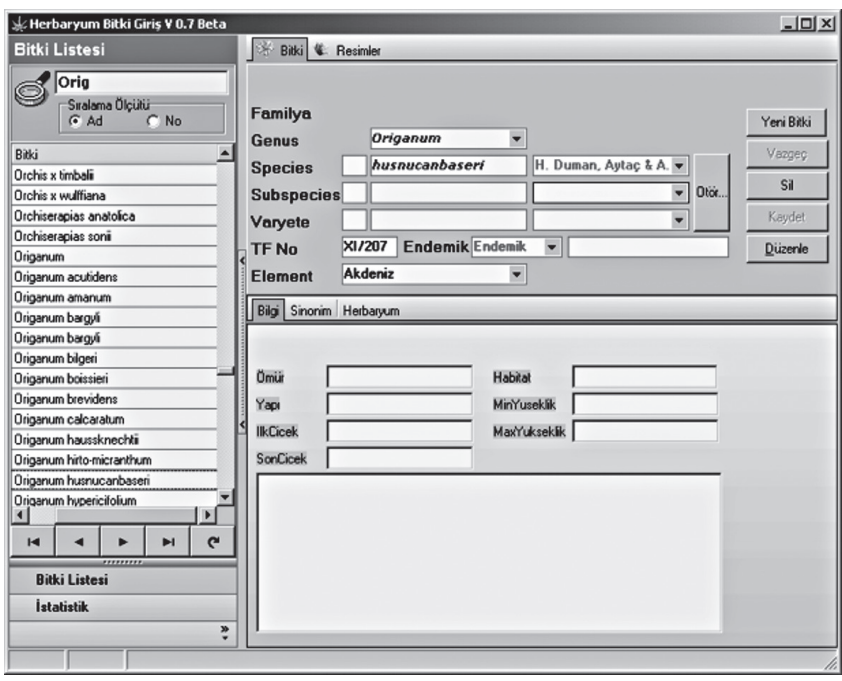

Resim 3: Türkiye florası bitkileri veri giriş ekranı

6. Bir herbaryumun sanal hale dönüştürülmesi aşamalarının zihinlerde net olarak canlandırılamamas1,

7. Herbaryumlardaki örneklere ait olası teşhis hatalarının ortaya çıkması konusundaki endişeler.

Sanal herbaryuma dönüşüm sürecinin doğal evrimsel gelişiminde kaçınılmaz adımlardan biriside ulusal ölçekli bir entegrasyondur. Araştırmacıların sorgulama yapabilecekleri ulusal ve kapsamlı bir sanal herbaryumlar ağı bu dönüşümün evrineceği ana hedeftir. Bu bağlamda değerlendirilmesi gereken önemli bir nokta da bir ülkede hatta kıtada, adım adım sanal hale dönüşen herbaryumların alt yapı ve yerel çözüm farklılıklarının ileride söz konusu olabilecek bir entegrasyonda engele dönüşebileceğidir (5, 29). Bu sorunun giderilmesine yönelik bir ortak aklın devreye sokularak, dönüşümün geneli kapsayacak eş güdümlü bir proje dahilinde gerçekleşmesi devrimsel nitelikte olacaktır. Böylece deneyimler çok sesli ve eş zamanlı olarak ortaya konabilecek, taksonomikrevizyonlar hızla uygulamaya sokulabilecek, olası en kapsamlı ve en etkin dönüşüm gerçekleştirilebilecektir. Bir diğer yol da, gerçekleşecek dönüşümün aynı temel yazılım alt yapısının adım adım yeni herbaryumlara aktarılması şeklinde yürütülmesidir. Ancak hızla gelişen bilgi teknolojileri alanında zamanla kaçınılmaz olarak gelişebilecek ana yazılımın, önceki herbaryumlara adaptasyonunda bir zorluğun ortaya çıkabileceği göz ard1 edilmemelidir.

Bitkisel kökenli doğal ilaç hammaddesi araştırmaları temel olarak beş ana safhada yürütülmektedir:

1. Bitkisel materyalin temini,

2. Elde edilen bitkisel materyalin nitel ve nicel analizleri,

3. Bazen eş zamanlı da yürütülebilen biyolojik etki rehberli saflaştırma ve kimyasal yapı tayini araştırmaları,

4. In-vitro, in-vivo ve klinik biyolojik etki ve toksisite araştırmaları,

5. Farmasötik olarak değerli bileşiklerin endüstriyel ölçekte üretimine yönelik araştırmalar

$\mathrm{Bu}$ aşamaların ilkinde araştırılan bitkiye ait morfolojik özelliklerin, çiçeklenme tarihinin ve önceden toplandığ1 yerlere

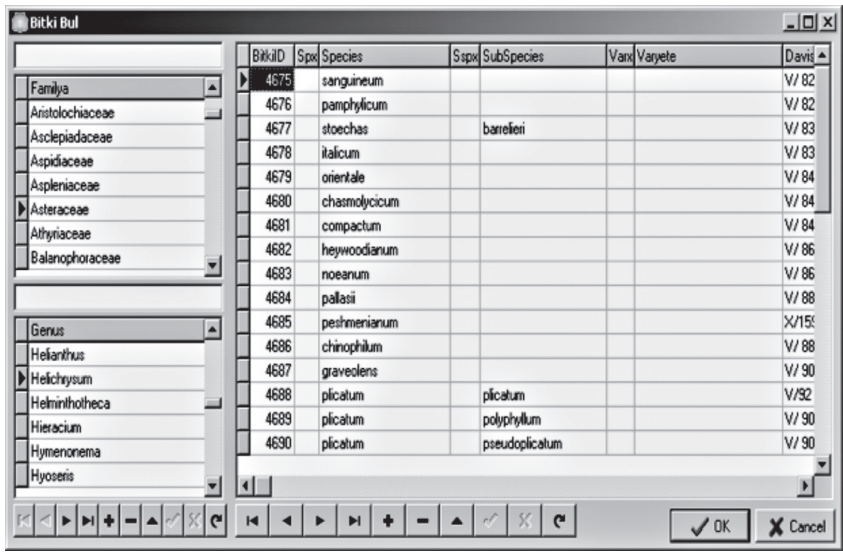

Resim 4: Sistematik sorgulama ekranı

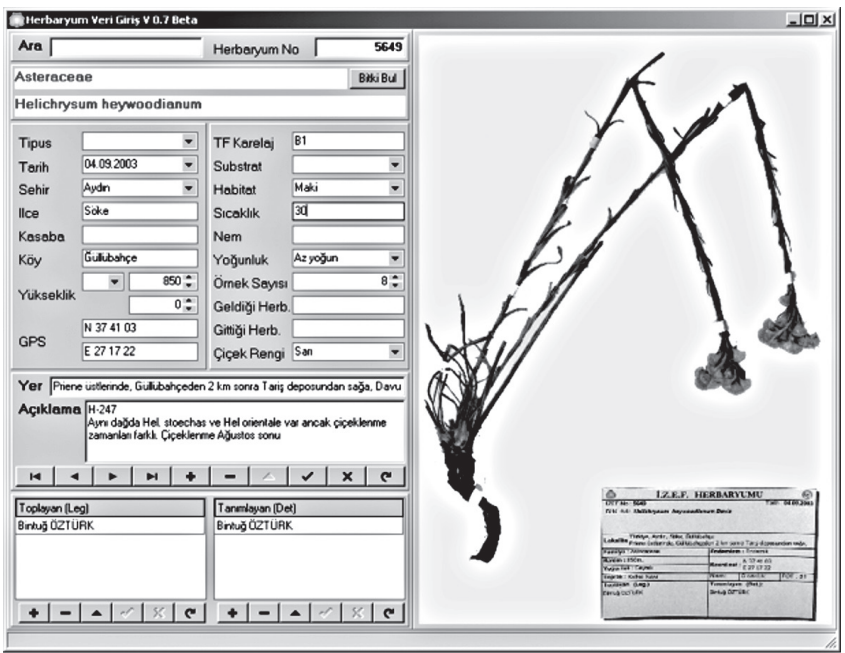

Resim 5: Herbaryum veri giriş ekranı

Tablo 1: IZEF herbaryum veri giriş yüzünde yer alan bilgi paketleri

\begin{tabular}{|l|l|l|}
\hline 1. Herbaryumno & 11. Yükseklik üst sınır & 21. Geldiği herbaryum \\
\hline 2. Familya & 12. Enlem koordinatları & 22. Gittiği herbaryum \\
\hline 3. Bitki adı & 13. Boylam koordinatları & 23. Çiçek rengi \\
\hline 4. Tipus & 14. Türkiye florası karesi & 24. Yer \\
\hline 5. Toplama tarihi & 15. Substrat & 25. Açıklama (ek bilgi) \\
\hline 6. Şehir & 16. Habitat & 27. Toplayan (Leg.) \\
\hline 7. İlçe & 17. Sıcaklığı & 28. Tanımlayan (Det.) \\
\hline 8. Kasaba & 18. Nem & 29. Örnek Resmi \\
\hline 9. Köy & 19. Lokalitedeki yoğunluk & \\
\hline 10. Yükseklik alt sınır & 20. Örnek (duplikat) sayıs1 & \\
\hline
\end{tabular}


ait bilgilerin herbaryumlardan tek tek ziyaret yoluyla temin edilmektedir. Araştırılan birkaç yakın taksonun, onlarca şehirdeki, onlarca herbaryumda yer alan, yüzlerce örneğine ait görüntü ve bilgilere uzaktan ulaşılabilmesi araştırma için harcanan emeğe, süreye ve kaynağa çok değerli katkılar sunabilmektedir. Herbaryum veritabanı yazılımı sayesinde örnek etiketine yazılabilecek bilgiler dışında örneğe, lokaliteye ve toplama zamanındaki diğer değişkenlere ait ilave bilgiler kaydedilebilmektedir. İlaç hammaddesi araştırmaları planlayanların korkulu rüyası, sınırlı bilgi yer alan herbaryum etiketlerindeki lokaliteye binbir zahmetle gidip,yanlış örneğe ulaşmak, örneği bulamamak ya da çok az miktarda örneğe ulaşabilmektir. Herbaryumveritabanında bitkinin toplandığ 1 lokalitedeki bitki yoğunluğu,az yoğun, biraz, orta yoğun, biraz bol ve yaygın şeklinde, 5'li bir skala ile derecelendirilmiştir. Böylece sonraki araştırmacıların hedef lokalite belirlerken, bu veriler ışı̆̆ında planlama yapabilmesine imkan tanınmış ve yeterli materyal toplayabilmek konusunda başta zaman olmak üzere kaynaklarını etkin kullanmalarına katkı sağlanmıştır.

Bir diğer sunulan çözüm ise bitkisel materyalin taşıması olası etkin maddelerin miktarını ve stabilitesini etkileyebilecek verilerin girişine imkan tanınmış olmasıdır. Bu sayede yeterli ve dikkatli kayıt girilmesi durumunda, araştırmacıların toplanan materyalde bulunabilecek etkin madde miktarı ile ilgili sıcaklık, 1ş1k ve nem gibi değişkenler konusunda yorum yapabilmeleri mümkün olabilecektir.

Türkiye florasında yer alan bitkilere ait kısıtlı lokalite bilgileri, ayrıntı içermeksizin "Türkiye ve Doğu Ege Adaları Florası" adlı ana kaynakta yer almaktadır. Sadece Eczacılık fakültelerinde bulunan herbaryumlarda 125.000 'den fazla bitkiye ait örnek ve kayıt bulunmaktadır. Bu rakamın Türkiye'deki tüm herbaryumlar değerlendirildiğinde 600.000'i aşacağı öngörülebilir (7-9). Her geçen gün gelişen ve zenginleşen herbaryumlardakilokalite kayıtları ise, ana kaynaktan çok daha ayrıntılı ve kapsamlıdır. Bitkilere ait tüm lokalite bilgileri ve görüntülerinin ayrıntılı olarak kaydedilebileceği, sorgulanabileceği ve yönetilebileceği, uzaktan ulaşılabilir ve hılı güncellenen sanal herbaryumların oluşturulması ise, modern bilimsel altyapıya sahip ülkelerdeki gibi belli bir süre içerisinde kaçınılmaz olarak gerçekleşecektir.

Özellikle tıbbi bitkilerce zengin sınırlı sayıdaki bitki kaydı bir avantaj olarak kullanılan IZEF modeli ile,bu devrimsel dönüşümde iyi bir örnekortaya konmuştur. Başta bitki örneği sayısı çok olan herbaryumlar olmak üzere, Türkiye'deki herbaryumların süratle sanal hale dönüşmesi, zengin bitkisel biyoçeşitliliğimize ait verilerin etkin yönetilmesinin yanısıra, başta yeni ilaç hammaddesi araştırmaları olmak üzere, bitkiyle çalışan tüm disiplinlerdeki araștırmacılarımızın elini güçlendirerek, uluslararası bilimsel işbirliği zemindedaha etkin yer alabilmelerine katkı sağlayacaktır.

\section{ABSTRACT}

AIM: The aim of this study is to present a key map for evolution to virtual herbarium based on IZEF (Izmir, Ege University Faculty of Pharmacy Herbarium)- the first virtual herbarium of Turkey and to express the important role of virtual herbariums on researchs about plant sourced new medicinal lead molecules.

METHOD: Data and images of 6000 herbarium material are transferred into virtual medium with computerized databases named "TürkiyeFlorası 1.0" and "IZEF Herbaryum1.0"that we developed.

RESULTS: The first virtual herbarium IZEF is subordinated for researchers via www.izef.ege.edu.tr, with all data and images of herbarium specimens.

Key Words: Virtual herbarium, herbarium, IZEF, Turkish flora

\section{KAYNAKLAR}

1. Baytop A. PiereBelon (1517-1564) ve Doğu Akdeniz gezisinin botanik yönü. HerbaMedica 2000;6:14-19.

2. Baytop A. Türkiye'de Botanik Tarihi Araştırmaları.Tübitak Yayınları, Akademik dizi 3,Yenigün matbaas1, Ankara. 2004.

3. Delgade M, Fajardo W, Gibaja E, Perez-PerezR. BioMen: an informationsystemtoherbarium. Expert Systemwith Applications 2005; 28:507-18.

4. Sankara Rao K, Sringeswara AN, Kumar D, Pulla S, Sukumar R. A digitalherbarium for the flora of Karnataka. CurrentScience 2012; 102:1268-71.

5. Barkworth ME, Murrell ZE. The US Virtual Herbarium: working with individual herbaria to build a national resource. ZooKeys 2012; 209:55-73.

6. Babaç MT. Possibility of an information system on plants of SouthWest Asia with particular reference to the Turkish plants data service (TUBIVES). Turk J Bot 2004; 28:119-27.

7. Ege MA, Öztürk B. İnteraktif Herbaryum Uygulamalarında "IZEF Herbaryum1.0" ve "Türkiye Floras1 1.0" Programları. BİHAT-Erzurum 2006, bildiri kitabi S-4.

8. Ege MA, Öztürk B, Zeybek U. Türkiye'nin ilk interaktif herbaryumu: http://̇zef.ege.edu.tr. BİHAT-Eskişehir 2002, bildiri kitabı B-44.

9. Öztürk $B, E g e M A$. Türkiye'nin ilk sayisal fiziki fitocoğrafyaharitasi“Türkiye Fitocografya Haritası 0.1Beta". BİHAT-Mersin 2010, bildiri kitab1 S-13.

10. Yelken T, Ege MA, Öztürk B. Farmakognozi ve fitoterapi derneği (FFD) monograflarıveritaban1. BİHAT-Antalya 2012, bildiri kitab1 P-85.

11. Öztürk B, Sadıkoğlu N, Erel ŞB, Ege MA. Türkiye'nin etnofarmasötik botanik kullanımı bulunan bitkileriveritabanı. BİHAT-Antalya 2012, bildiri kitabı P-81.

12. Öztürk B, Kutlu D, Erel ŞB, Ege MA. Türkiye tibbi bitkileri bibliyografyasi veritabanı. BİHAT-Antalya 2012, bildiri kitabı P-82.

13. Urhan Y, Cebe GE, Öztürk B, Ege MA, Koyu EB. The edible plants data base of Turkey. Proceedings of $11^{\text {th }}$ International Ethnobotany Symposio Antalya 2013, pp-168.

14. Davis PH, Cullen J, Coode MJE. Flora of Turkey and the East Aegean Islands. Edinburgh University Press, Vol.1 Edinburgh. 1965.

15. Davis PH, Cullen J, Coode MJE. Flora of Turkey and the East Aegean Islands. Edinburgh University Press, Vol.2 Edinburgh. 1967.

16. Davis PH, Chamberlain DF, Matthews VA. Flora of Turkey and the 
East Aegean Islands. Edinburgh University Press, Vol.3 Edinburgh. 1970.

17. Davis PH, Chamberlain DF, Phil D, Matthews VA. Flora of Turkey and the East Aegean Islands. Edinburgh University Press, Vol.4 Edinburgh. 1972.

18. Davis PH, Matthews VA, Kupicha FK, Parris BS. Flora of Turkey and the East Aegean Islands. Edinburgh University Press, Vol.5 Edinburgh. 1975.

19. Davis PH, Edmondson JR, Mill RR, Parris BS. Flora of Turkey and the East Aegean Islands. Edinburgh University Press, Vol.6 Edinburgh. 1978.

20. Davis PH, Edmondson JR, Mill RR, Tan K. Flora of Turkey and the East Aegean Islands. Edinburgh University Press, Vol.7 Edinburgh. 1982.

21. Davis PH, Mill RR, Tan K. Flora of Turkey and the East Aegean Islands. Edinburgh University Press, Vol.8 Edinburgh. 1984.

22. Davis PH, Mill RR, Tan K. Flora of Turkey and the East Aegean Islands. Edinburgh University Press, Vol.9 Edinburgh. 1985.
23. Davis PH, Mill RR, Tan K. Flora of Turkey and the East Aegean Islands. Edinburgh University Press, Vol.10 Edinburgh. 1988.

24. Güner A, Özhatay N, Ekim T, Baser KHC.F lora of Turkey and the East Aegean Islands. Edinburgh University Press, Vol.11 Edinburgh. 2000.

25. Stroustrup B. The $\mathrm{C}++$ programming language. $2^{\text {th }}$ edition Addison-Wesley Publishing Company NewYork. 1995.

26. Eşbah $\mathrm{H}$, Tunçay AA. Peyzaj bitkilerine ilişkin özgün bir veritaban geliştirilmesi. ADÜ Ziraat Fakültesi Dergisi 2005; 2, (2): 43-50.

27. Avalos A, Barrera A, Gabriel y Galán JM, Gallardo Gómez, Hernández JM, Lahoz R, López P, Marcos N, Martin L, Moreno A, Oliván G, Pérez-Urria E, Pintos B. UCM-MACB 2.0: A complutense university virtual herbarium project. Proceedings of Edulearn 11 Conference Barcelona. 2011.

28. Hitchcock A. NPS herbaria go global. Proceedings of George WrigthSociety Conference on Parks. 2011.

29. Bakış Y, M. Tekin Babaç MY, Uslu E.Updates and improvements of Turkish plants data service. HIBIT-2011;5:136-40. 